\title{
A BIBLIOMETRIC STUDY OF INDIAN JOURNAL OF INFORMATION LIBRARY AND SOCIETY DURING 2012 - 2016
}

\author{
Dr. Santu Ram Kashyap \\ Sr. Assistant Professor, SOS in Library \& information Science, \\ PT. Ravishankar Shukla University, Raipur(C.G.), India
}

\begin{abstract}
The papers present Bibliometric study of Journal of Information Library and society during 2012 to 2016. This study analysis the different aspect of the journal with statically such as-year wise Distribution of article, cumulative total of article, Authorship Pattern, State wise distribution of article, Page lengths of the article and Types of Cited Documents. It found that out of 141 articles.The maximum 35 (24.82\%) articles Published in the year 2016 and the minimum 21 (14.89\%) articles Published in the year 2014. Also out of 233 contributors. 71(30.47\%) Articles were contributed by single authors, $104(46.63 \%)$ contributions by two authors, $54(23.17 \%)$ contributions by three authors, and 04(1.7\%) 24 contributions by four authors. the highest 252 (24.34\%) Document cited in the year 2012 and lowest 108 (10.43\%) Document cited in the year 2013.
\end{abstract}

Key words: Bibliometrics study, Journal of Information Library and society.

Cite this Article: Dr. Santu Ram Kashyap, A Bibliometric Study of Indian Journal of Information Library and Society During 2012 - 2016, International Journal of Library \& Information Science, 7(1), 2018, pp. 35-40.

$\mathrm{http} / /$ iaeme.com/Home/issue/IJLIS?Volume=7\&Issue=1

\section{INTRODOCTION}

Periodical are one types of very useful information sources of library it's provide new knowledge, new theory \& thought, research trends \& development to users regarding any discipline. In this context the Indian journal of information library \& society are well known quarterly research journal field in the library and information science. It journal started from 1988. It publish June \& December every year from Cuttack Odisha. The editor of the journal is Param bhushan Dr. Bana bihari Shukla and Advisory editorial board chairman Professor V. V. Kulkarni. it journal published original research papers and survey report field in the Library Management, ICT Appalication in libraries, Electronic Information resources, Bibliometrics, Knowlwdge Management and E- Consourtium etc. the purpose of this journal is disseminate new ideas and research output to globle community. field in the Library in Information science. 
The term Bibliometric was first used by Alan Pritchard in 1996. Bibliometric study is a statistical Analysis of books and journals field in the Library \& Information Science.

\section{REVIEW OF LITERATURE}

Kamble and Pradeepa(2015) studied on bibliometric Analysis of Hematology during 2004 2013 as a result they found the highest numbers of publication $28,283(11.30 \%)$ were published in year 2013. Maximum Numbers of the publication $778(0.31 \%)$ contributed by Martinelli G. with first rank and $597(0.24 \%)$ publication contributed by Kim Hj with $10^{\text {th }}$ rank. Krishnan and Raja (2015) Analyzed the research productivity of journal of optics with a Scientrometric study. he found Maximum Number of the article published $51(20 \%)$ in the year 2012. and Minimum numbers of the Article published 24 (10\%) in the year 2010 and the journal article 1197 (42.4\%) highest cited by the contributors. Betageri (2015) studied bibliometric Analysis of the journal of the Dairying food and home sciences from 2003 2012. he found maximum numbers $65(12 \%)$ of the article published in the year 2012 and minimum numbers $42(8 \%)$ of the article published in the year 2004. Regarding citation the volume number 31 of 2012 having highest citation with 731 (14\%) and volume number 26 of 2007 having lowest citation with 384 (7\%). Most of the article $283(52 \%)$ have 1-4 pages length, $225(42 \%)$ have 5-8 pages length \& $34(6 \%)$ have 8 - above pages length. Bapte (2017) Analyzed 4,821 citation appended to papers published in DESIDOC Journal of Library and Information technology (DJLIT) during 2011 - 2015 he found that dominance of single authorship with 1912 (39.68\%). 1152 (23.89\%) citation with two authors 456 (9.54\%) citation with three authors and $386(8 \%)$ citation with more than three authors. the Degree of collaboration of this study was 0.51 . Dr. B. M. Gupta was most prolific author with 52 citations. Dr. K. C. Garg second and Dr. B.S. Kademani were third position respectively.

\section{SCOPE AND LIMITATIONS}

The Scope of the present study confined with Indian journal of Information Library\& society period 2000 to 2014. The limitation of the Study are that it does not consider any other journals of library and information science.

\section{METHODOLOGY}

The present study based on Bibliometric Methods it is a stastical methods it Analyze the different aspect of books and journals such as - year wise distribution of article, Authorship Pattern, state wise distribution of article and Author, page length \& Degree of collaboration etc.

\section{OBJECTIVES}

The main objective of this Study are as follows

- To know the Year wise Distribution of Article

- To know Yearly distribution of cumulative total of Article

- To know Authorship Pattern

- To Study State wise distribution of Article

- To know Page lengths of the Article

- $\quad$ To Study Types of Cited Documents 


\section{DATA ANALYSIS AND INTERPRITATION}

Table 1 year wise Distribution of Article

\begin{tabular}{|c|c|c|c|c|}
\hline S. NO. & Year & Volume & Article & Percentage \% \\
\hline 1 & 2012 & 25 & 24 & $17.02 \%$ \\
\hline 2 & 2013 & 26 & 31 & $21.98 \%$ \\
\hline 3 & 2014 & 27 & 21 & $14.89 \%$ \\
\hline 4 & 2015 & 28 & 30 & $21.27 \%$ \\
\hline 5 & 2016 & 29 & 35 & $24.82 \%$ \\
\hline & Total & & $\mathbf{1 4 1}$ & $\mathbf{1 0 0 \%}$ \\
\hline
\end{tabular}

Table -1 Show the year wise distribution of articles in the $2012-2016$. The maximum 35 (24.82\%) articles Published in the year 2016 and the minimum 21 (14.89\%) articles Published in the year 2014.The Percentages ranges varies from $14.89 \%$ to $24.82 \%$.

Table 2 Year wise Cumulative Distribution of Publications

\begin{tabular}{|c|c|c|c|c|c|}
\hline S. NO. & year & Volume & Article & $\begin{array}{c}\text { Cumulative } \\
\text { frequency }\end{array}$ & $\begin{array}{c}\text { Cumulative } \\
\text { Percentage \% }\end{array}$ \\
\hline 1 & 2012 & 25 & 24 & 24 & $17.02 \%$ \\
\hline 2 & 2013 & 26 & 31 & 55 & $39.00 \%$ \\
\hline 3 & 2014 & 27 & 21 & 76 & $53.90 \%$ \\
\hline 4 & 2015 & 28 & 30 & 106 & $75.17 \%$ \\
\hline 5 & 2016 & 29 & 35 & 141 & $100 \%$ \\
\hline & Total & & $\mathbf{1 4 1}$ & $\mathbf{1 4 1}$ & $\mathbf{1 0 0} \%$ \\
\hline
\end{tabular}

The study further attempt to find out the cumulative frequency and cumulative percentage of the publications under the scope of the study and the same has been presented in the above table.

Table 3 Authorship Pattern

\begin{tabular}{|c|c|c|c|c|c|c|c|}
\hline \multirow{2}{*}{ S. NO. } & \multirow{2}{*}{ Year } & \multirow{2}{*}{ Volume } & \multicolumn{4}{|c|}{ No of Authors } & \multirow{2}{*}{ Total } \\
\hline & & & One & Two & Three & Four & \\
\hline 1 & 2012 & 25 & 08 & 24 & 09 & 04 & 45 \\
\hline 2 & 2013 & 26 & 17 & 20 & 15 & 00 & 52 \\
\hline 3 & 2014 & 27 & 12 & 18 & 00 & 00 & 30 \\
\hline 4 & 2015 & 28 & 11 & 28 & 15 & 00 & 54 \\
\hline \multirow[t]{2}{*}{5} & 2016 & 29 & 23 & 14 & 15 & 00 & 52 \\
\hline & Total & & 71(30.47\%) & $104(46.63 \%)$ & $54(23.17 \%)$ & $04(1.7 \%)$ & 233 \\
\hline
\end{tabular}

Table- 3 which is relatetd year wise authorship pattern show that out of 233 contributors. $71(30.47 \%)$ Articles were contributed by single authors, 104(46.63\%) contributions by two authors, 54(23.17\%) contributions by three authors, and 04(1.7\%) 24 contributions by four authors.

Table 4 State wise distribution of Article

\begin{tabular}{|c|c|c|c|c|c|c|c|c|}
\hline \multirow{2}{*}{ Rank } & \multirow{2}{*}{ Name of State } & \multicolumn{5}{|c|}{ Article } & \multirow{2}{*}{ Total } & \multirow{2}{*}{$\begin{array}{c}\text { Percentages } \\
\%\end{array}$} \\
\hline & & 2012 & 2013 & 2014 & 2015 & 2016 & & \\
\hline 1 & Odisha & 4 & 5 & 9 & 8 & 10 & 36 & $25.53 \%$ \\
\hline 2 & Telangana & 3 & 2 & 0 & 14 & 7 & 26 & $18.43 \%$ \\
\hline
\end{tabular}


A Bibliometric Study of Indian Journal of Information Library and Society During 2012 - 2016

\begin{tabular}{|c|c|c|c|c|c|c|c|c|}
\hline 3 & Tamilnadu & 7 & 6 & 2 & 1 & 2 & 18 & $12.76 \%$ \\
\hline 4 & Utter Pradesh & 2 & 2 & 2 & 2 & 3 & 11 & $7.80 \%$ \\
\hline 5 & Rajsthan & 1 & 2 & 0 & 3 & 4 & 10 & $7.09 \%$ \\
\hline 5 & Andhra Pradesh & 1 & 6 & 2 & 0 & 1 & 10 & $7.09 \%$ \\
\hline 6 & Karnataka & 2 & 1 & 2 & 1 & 0 & 6 & $4.25 \%$ \\
\hline 6 & Punjab & 0 & 3 & 1 & 0 & 2 & 6 & $4.25 \%$ \\
\hline 7 & Maharashtra & 2 & 0 & 0 & 1 & 2 & 5 & $3.54 \%$ \\
\hline 8 & Madhya Pradesh & 0 & 1 & 0 & 0 & 3 & 4 & $2.83 \%$ \\
\hline 8 & West Bengol & 1 & 2 & 1 & 0 & 0 & 4 & $2.83 \%$ \\
\hline 9 & Uttarakhand & 1 & 0 & 2 & 0 & 0 & 3 & $2.12 \%$ \\
\hline 10 & kerala & 0 & 1 & 0 & 0 & 0 & 1 & $0.70 \%$ \\
\hline 10 & Goa & 0 & 0 & 0 & 0 & 1 & 1 & $0.70 \%$ \\
\hline \multicolumn{7}{|c|}{ Total } \\
\hline
\end{tabular}

The Analysis of Table 4 Show the State wise distribution of Article. The highest numbers of the contributions are from odisha with first rank $36(25.53 \%)$ Followed by Telangana 26 (18.43\%), Tamilnadu 18 (12.76\%), Utter Pradesh11 (7.80\%) Rajsthan and Andhra Pradesh 10 (7.09\%), Karnatka and Paunjab 6 (4.25\%), Maharashtra 5(3.54\%), Madhya Pradesh and West Bengal 4 (2.83\%), Uttarakhand 3 (2.12\%) and Kerala \& Goa. $1(0.60 \%)$.

Table 5 Page lengths of the Articles

\begin{tabular}{|c|c|c|c|c|c|c|c|}
\hline \multirow{2}{*}{ Page length } & \multicolumn{5}{|c|}{ Page length } & \multirow{2}{*}{ Total } & \multirow{2}{*}{$\begin{array}{c}\text { Percentages } \\
\%\end{array}$} \\
\hline & 2012 & 2013 & 2014 & 2015 & 2016 & & \\
\hline Two pages & 0 & 0 & 0 & 0 & 1 & 1 & $0.70 \%$ \\
\hline Three pages & 0 & 1 & 0 & 2 & 5 & 8 & $5.67 \%$ \\
\hline Four pages & 0 & 2 & 0 & 0 & 0 & 2 & $1.41 \%$ \\
\hline Five pages & 0 & 2 & 0 & 4 & 3 & 9 & $6.38 \%$ \\
\hline Six psges & 1 & 3 & 2 & 2 & 3 & 11 & $7.80 \%$ \\
\hline Seven pages & 3 & 2 & 2 & 3 & 3 & 13 & $9.21 \%$ \\
\hline Eight pages & 1 & 3 & 2 & 3 & 3 & 12 & $8.51 \%$ \\
\hline nine pages & 1 & 5 & 1 & 0 & 3 & 10 & $7.09 \%$ \\
\hline Ten pages & 4 & 5 & 5 & 4 & 2 & 20 & $14.18 \%$ \\
\hline Eleven pages & 3 & 5 & 3 & 2 & 1 & 14 & $9.92 \%$ \\
\hline Twelve pages & 3 & 1 & 0 & 3 & 2 & 9 & $6.38 \%$ \\
\hline Thirteen pages & 3 & 0 & 1 & 0 & 2 & 6 & $4.25 \%$ \\
\hline Fourteen pages & 1 & 1 & 1 & 1 & 1 & 5 & $3.54 \%$ \\
\hline Fifteen pages & 1 & 1 & 0 & 1 & 0 & 3 & $2.12 \%$ \\
\hline Sixteen pages & 0 & 0 & 0 & 1 & 1 & 2 & $1.41 \%$ \\
\hline Seventeen pages & 0 & 0 & 1 & 0 & 1 & 2 & $1.41 \%$ \\
\hline Eighteen pages & 1 & 0 & 0 & 1 & 0 & 2 & $1.41 \%$ \\
\hline Nineteen pages & 0 & 0 & 0 & 0 & 0 & 0 & $0.00 \%$ \\
\hline Twenty pages & 0 & 0 & 0 & 0 & 1 & 1 & $0.70 \%$ \\
\hline Twenty one pages & 1 & 0 & 0 & 0 & 1 & 2 & $1.41 \%$ \\
\hline Twenty Two pages & 1 & 0 & 0 & 1 & 1 & 3 & $2.12 \%$ \\
\hline $\begin{array}{l}\text { More Than Twenty } \\
\text { one pages }\end{array}$ & 0 & 0 & 3 & 2 & 1 & 6 & $4.25 \%$ \\
\hline \multicolumn{6}{|c|}{ Total } & 141 & $100 \%$ \\
\hline
\end{tabular}


The data Analysis of Table- 5 Show that $1(0.70 \%)$ articles have the length of Two pages, 8 (5.67 $\%)$ articales have the length of Three pages, $2(1.41 \%)$ articales have the length of four pages, $9(6.38$ $\%)$ articales have the length of five pages, $11(7.80 \%)$ articales have the length of six pages $13(9.21$ $\%)$ articales have the length of seven pages, $12(9.51 \%)$ articales have the length of thirteen and eight pages, $10(7.09 \%)$ articales have the length of nine pages, $20(14.18 . \%)$ articales have the length of Ten pages, $14(9.92 \%)$ articales have the length of eleven pages, $9(6.38 \%)$ articales have the length of Twelve pages $6(4.25 \%)$ articales have the length of Thirteen pages, $5(3.54 \%)$ articales have the length of fourteen pages, $3(2.12 \%)$ articales have the length of fifteen pages, $2(1.41 \%)$ articales have the length of sixteen pages, $2(1.41 \%)$ articales have the length of seventeen pages, $2(1.41 \%)$ articales have the length of eighteen pages, $1(0.70 \%)$ articales have the length of Twenty pages, $2(1.41 \%)$ articales have the length of Twenty one pages, $3(2.12 \%)$ articales have the length of Twenty Two pages, and $6(4.25 \%)$ articales have the length of more than Twenty one pages.

Table 6 Year wise distribution of cited documents

\begin{tabular}{|c|c|c|c|c|}
\hline S. NO. & Year & Volume & $\begin{array}{c}\text { No of cited } \\
\text { documents }\end{array}$ & Percentages \% \\
\hline 1 & 2012 & 25 & 252 & $24.34 \%$ \\
\hline 2 & 2013 & 26 & 224 & $21.64 \%$ \\
\hline 3 & 2014 & 27 & 244 & $21.64 \%$ \\
\hline 4 & 2015 & 28 & 207 & $20 \%$ \\
\hline 5 & 2016 & 29 & 108 & $10.43 \%$ \\
\hline & Total & & $\mathbf{1 0 3 5}$ & $\mathbf{1 0 0 \%}$ \\
\hline
\end{tabular}

A perusal table- 10 Show the year wise cited Documents by the authors of the Indian Journal of information library \& society. It Indicates that the highest $252(24.34 \%)$ Document cited in the year 2012 Followed by 224 (21.64\%), Document cited in the year 2013 \& 2014, 207 $(20 \%)$ Document cited in the year 2015 and 108 (10.43\%) Document cited in the year 2016.

\section{FINDINGS}

1. The maximum $35(24.82 \%)$ articles Published in the year 2016 and the minimum 21 $(14.89 \%)$ articles Published in the year 2014.The Percentages ranges varies from $14.89 \%$ to $24.82 \%$.

2. Out of 233 contributors. $71(30.47 \%)$ articles were contributed by single authors, $104(46.63 \%)$ contributions by two authors, $54(23.17 \%)$ contributions by three authors, and $04(1.7 \%) 24$ contributions by four authors.

3. The highest numbers of the contributions are from odisha $36(25.53 \%)$ and lowest numbers of the contributions are from Kerala \& Goa. 1(0.60\%).

4. Majority of the articles i.e. $20(14.18 \%)$ have the length of Ten pages \& minimum numbers of the articles $1(0.70 \%)$ articales have the length of two\& twenty pages.

5. The highest $252(24.34 \%)$ Document cited in the year 2012 Followed by 224 (21.64\%), Document cited in the year 2013 \& 2014, 207 (20\%) Document cited in the year 2015 and $108(10.43 \%)$ Document cited in the year 2016 .

\section{CONCLUSION}

On the basis of findings as a result found that during the study period $2012-2016$ the journal has published 141. The maximum $35(24.82 \%)$ articles Published in the year 2016 and the minimum $21(14.89 \%)$ articles Published in the year 2014.The Percentages ranges varies from $14.89 \%$ to $24.82 \%)$. out of 233 contributors. $71(30.47 \%)$ Articles were contributed by single authors, $104(46.63 \%)$ contributions by two authors, 54(23.17\%) contributions by three authors, and 
04(1.7\%) 24 contributions by four authors. The highest numbers of the contributions are from odisha $36(25.53 \%)$ and lowest numbers of the contributions are from Kerala \& Goa. $1(0.60 \%)$. Majority of the articles i.e. $20(14.18 \%)$ have the length of Ten pages \& minimum numbers of the articles $1(0.70 \%)$ articales have the length of two\& twenty pages.

\section{REFERENCES}

[1] Kamble Shivanand D. \& Pradeepa H. Bibliometric Analysis of Hematology during 2004 2013. Journal of Advances in Library and Information sciences. 4, 1, (2015) pp 21-25.

[2] Krishan V. \& Raja S. Research productivity of journal of optics: A Scientrometric study. Journal of Advances in Library and Information sciences. 4, 2. (2015) pp 177-181.

[3] Shanta S, Betageri. Bibliometric Analysis of contribution in the journal of Dairying, food and home sciences from 2003 - 2012. Journal of Advances in Library and Information sciences.4, 1. (2015) pp 86-89.

[4] Bapte Vishal Dattatray. DESIDOC Journal of Library and Information Technology (DJLIT): A Bibliometric Analysis of cited Reference. DESIDOC Journal of Library and Information Technology. 37, 4. (2017) pp $264-269$.

[5] Nagarkar Shubhada, Veer Chaitanga \& Kumbhar Rajendra . Bibliometric Analysis of papers published by faculty of Life science Department of Savitribai phule pune university during 1999 - 2013. DESIDOC Journal of Library \& Information Technology 35, 5.(2015). Pp $368-375$.

[6] A. jessy, Rao Mahabaleshwara \& K. Shivananda Bhat. Citation Analysis of Acadmic publication to Identify subscribed Journal Usase: A case study. DESIDOC Journal of Library \& Information Technology 36, 4,(2016). Pp 194 - 198

[7] Garg K. C. \& Sharma Chetan. Bibliometric of Library and Information science research in india during 2004 - 2015. DESIDOC Journal of Library \& Information Technology 37, 3. (2017). Pp 221- 227.

[8] T. Raja \& K. Murugan. A Bibliometric study on research and Reflections on Education. Journal of Advances in Library and Information sciences. 4, 3. (2015) pp 228-232.

[9] A. Vellaichamy \& R. Jeyshankar. Bibliometri Analysis of the journal Webometric from 2004 - 2013. Journal of Advances in Library and Information sciences. 4, 1. (2015) pp 86-89.

[10] L.S.R.C.V. Ramesh \& A.V.S.S. Naga Raju. Publication pattern in Indian journal of information, Library and society 2007 - 2014: A bibliometrc study. Indian journal of information, Library and society, 28,3 2015 pp $269-280$.

[11] Pandita, Ramesh. DESIDOC journal of Library and information Technology (DJLIT): metric study (2003 -12). Library philosophy and Practice( e- journal). 2014.

[12] Dr. Harish Kumar Sahu, A Bibliometric Analysis of Research Contribution in PEARL: A Journal of Library and Information Science, 2012-2016. International Journal of Library \& Information Science, 6(2), 2017, pp.26-33.

[13] Dr. Santu Ram Kashyap, A Bibliometric Study of International Research Journal of Library and Information Science Period 2011 - 2014. International Journal of Library \& Information Science, 6(5), 2017, pp. 113-121.

[14] Asifa Jan and Ridwana, Bibliometric Analysis of Indian Journal of Fisheries. International Journal of Library \& Information Science, 6(3), 2017, pp.06- 12.

[15] P. Raghunatha Reddy, A Bibliometric Study of Ph.D Awarded Theses in Department of Telugu Studies of Sri Venkateswara University During the Period 1964-1988, International Journal of Library and Information Science (IJLIS), Volume 3, Issue 1, January - June (2014), pp. 59-66 